\title{
De formación docente hacia subjetivación del maestro. Un giro epistémico necesario en el siglo xxı
}

\author{
Yamith-José Fandiño-Parra
}

\section{RESUMEN}

Este artículo de reflexión ${ }^{1}$ cuestiona el uso de formación docente y aboga por la asunción de la subjetivación del maestro como nueva categoría. Para tal fin, el artículo revisa las bases conceptuales de la formación docente, cuestiona los mecanismos que la operacionalizan y expone perspectivas teóricas que instalan la subjetivación como nuevo objeto de estudio. Dicha subjetivación implica entender al maestro como un actor ético-político, pedagógico-intelectual, socio-jurídico, histórico-cultural y comunicativoestético. Entre otras cosas, el artículo concluye que la comunidad educativa debe realizar un giro epistémico desde prácticas disciplinarias y mecanismos de control propios de la formación docente hacia asuntos como la conciencia histórica, la acción cultural y la enunciación promovidos por la subjetivación del maestro.

Palabras clave: formación docente, docencia, licenciaturas, innovación docente.

Yamith-José Fandiño-Parra

teacheryamith@gmail.com; yfandino@unisalle.edu.co Colombiano. Doctorando en Educación y Sociedad, Universidad de La Salle, Colombia; Magíster en Docencia, Universidad de La Salle, Colombia; Licenciado en Filología e Idiomas, Universidad Nacional, Colombia. Profesor-Investigador de tiempo completo, Facultad de Ciencias de la Educación, Universidad de La Salle, Colombia. Temas de investigación: estudios decoloniales, formación de docentes y enseñanza de una segunda lengua. ORCID: https://orcid.org/0000-0002-5567-5465.

\footnotetext{
${ }^{1}$ Artículo de reflexión derivado del marco teórico del proyecto de tesis doctoral titulada "Subalternización de formadores de docentes: prácticas de resistencia en programas de licenciatura en universidad privadas colombianas", planteada como producto de investigación para el grupo de investigación. Resolución de Problemas, Evaluación y Dificultades de Aprendizaje (PREVADIA), Colciencias, Colombia.
} 


\section{Da formação docente à subjetivação do professor. Um giro epistémico necessário no século $\mathbf{X X I}$}

\section{RESUMO}

Este artigo de reflexão questiona o uso da formação docente e defende a assunção da subjetivação do professor como nova categoria. Para tal fim, o artigo revisa as bases conceituais da formação docente, questiona os mecanismos que a operacionalizam e expõe perspectivas teóricas que instalam a subjetivação como novo objeto de estudo. Dita subjetivação implica entender o professor como um ator éticopolítico, pedagógico-intelectual, sociojurídico, histórico-cultural e comunicativo-estético. Entre outras coisas, o artigo conclui que a comunidade educativa deve realizar um giro epistémico de práticas disciplinarias e mecanismos de controle próprios da formação docente à assuntos como a consciência histórica, a ação cultural e a enunciação promovidos pela subjetivação do professor.

Palavras chave: formação docente, docência, licenciaturas, inovação docente.

\section{From teacher training to teacher subjectivation. A necessary epistemic shift in the 21st Century}

\section{ABSTRACT}

This reflection article challenges the use of teacher training and advocates the assumption of teacher subjectivation as a new category. To do so, the article reviews the conceptual bases of teacher training, questions the mechanisms that operationalize it and exposes theoretical perspectives that install subjectivation as a new object of study. Such subjectivation implies understanding the teacher as an ethical-political, pedagogical-intellectual, socio-legal, historical-cultural and communicative-aesthetic actor. Among other things, the article concludes that the educational community must carry out an epistemic shift from disciplinary practices and control mechanisms specific to teacher education towards issues such as historical awareness, cultural action and enunciation promoted by the subjectivation of the teacher.

Key words: teacher training, teaching, undergraduate studies, teacher innovation. 


\section{Introducción}

En las últimas décadas, maestros, investigadores y sectores interesados han procurado reflexionar y analizar la formación docente desde posturas teóricas como el constructivismo sociocultural o la hermenéutica reflexiva y apuestas metodológicas como el interpretativismo fenomenológico o la sociocrítica emancipatoria. En Colombia, trabajos como "Un diagnóstico de la formación docente en Colombia" de Calvo, Rendón y Rojas (2004) o "El maestro y su desarrollo profesional en Colombia" de Flaborea y Manrique (2019) han rastreado y cuestionado dinámicas y fuerzas, las cuales se han materializado en nuestro continente "en una agenda de políticas específicas (descentralización, focalización, autonomía escolar, etcétera) y en un conjunto de instrumentos (evaluación, currículum nacional, financiamiento por proyectos, etcétera) (Suasnábar, 2017: 21). Estas políticas e instrumentos ${ }^{2}$ han legitimado ciertos modos de ser, hacer, hablar y pensar a la vez que han negado otros modos posibles, alternativos $\mathrm{u}$ opcionales.

Sin duda, estos trabajos han permitido develar, rebatir y resistir epistemes y enfoques homogeneizadores, mercantilistas y neoliberales. No obstante, este artículo plantea que, aunque necesarios y útiles, estos adelantos no son suficientes, pues cuando se habla de formación docente priman aún perspectivas academicistas y tecnocrática-eficientistas que circunscriben y limitan la naturaleza y el alcance de las reformas educativas y los proyectos curriculares (ver Gil, 2018; Nieva y Martínez, 2016). Dichas perspectivas suelen someter, subyugar y circunscribir al maestro a ser un funcionario operario, un técnico ejecutor y un intelectual subalterno equipado con conocimientos, capacidades y hábitos con la finalidad de trasmitirlos, reproducirlos y/o instruirlos. Es de vital importancia, entonces, movilizar discursos y procesos para que ya no se hable de formación docente, sino que se piense en subjetivación del maestro como categoría fundante. Por ende, este artículo le propone a la comunidad educativa hacer un giro epistémico ${ }^{3}$ que asuma al maestro como actor ético-político, pedagógico-intelectual, socio-jurídico, histórico-cultural y comunicativo-estético dotado, entre otras cosas, con conciencia histórica, pensamiento crítico, pedagogía crítica transformativa y multialfabetización.

\section{De formación docente hacia subjetivación del maestro}

Inicialmente, se debe señalar que la formación constituye un campo de estudio que da cuenta de la adquisición y desarrollos de cualidades y potencialidades que se extienden a diversas áreas de la existencia humana (Buckley y Caple, 1991; García y García, 2001). Este campo cuenta, entonces, con posturas diversas pero complementarias como la naturalista-individualista de Rousseau, la históricaesencialista de Hegel y la autorreflexiva-existencialista de Gadamer. Igualmente, este campo considera diferentes tipos de formación, los cuales dimensionan cómo las personas dotan y se dotan de sentido mediante vivencias y acciones personales, socioculturales e histórico-políticas (ver Ortiz, 2006).

\footnotetext{
${ }^{2}$ Políticas e instrumentos que se constituyen en dispositivos de constitución de sujetos, entendidos por Sánchez-Amaya (2013: 756-757) como "mecanismos por excelencia de gestión y autogestión de sujetos tanto individuales como colectivos [...] una producción de sujetos homogéneos, normalizados, regularizados, evaluados, dóciles, obedientes, expuestos continuamente a diversos procedimientos de vigilancia y al control; permanentemente examinados".

${ }^{3}$ Hablar de giro epistémico conlleva pensar nuevos paradigmas que favorezcan el desarrollo de otras formas del pensar racional. Ante una racionalidad sintética, reductora, universal y monológica, se plantean una serie de alternativas sistémicas, complejas, multiversales y dialógicas que postulan nuevos elementos y aspectos. Estas alternativas permiten entender que "la realidad transcurre a partir y entre fenómenos no causales sino aleatorios, cuyos procesos de comprensión son complejos porque requieren ser vistos desde múltiples niveles de estructuración" (Velásquez, 2009: 151).
} 
En 1980, Honoré postula que la formación comprende varias esferas de la actividad humana (profesiones, instituciones, entornos, etcétera) e incorpora dinámicas personales y sociales derivadas, entre otras cosas, del trabajo y la cultura. Para él, la formación implica distintos ámbitos de la existencia como el biológico, el síquico y el social, los cuales avivan una relación dialéctica entre interior y exterior. Por su parte, Berbaum et al. (1982) plantean la necesidad de hablar de tres tipos de formación: autoformación, heteroformación e interformación. La autoformación da cuenta del trabajo intrínseco que lleva a cabo cada persona en pro de su desarrollo mientras que la heteroformación se relaciona con las distintas influencias que el sujeto recibe del mundo exterior. Por su parte, la interformación permite entender el rol de las acciones compartidas y la presencia de influencias recíprocas. En 1990, Zabalza propone entender la formación como un proceso de desarrollo que sigue el sujeto hasta alcanzar su plenitud personal con el propósito de trasformar los acontecimientos cotidianos en experiencias significativas.

Para Beillerot (1998), una revisión histórica permite reconocer tres sentidos asociados con formación: formación del espíritu, formación práctica y formación de vida. En el siglo XVIII, la formación daba cuenta de la adquisición rigurosa de una serie de aptitudes que enaltecían el potencial del espíritu humano y la facultad del razonamiento. En el siglo XIX, la formación se asociaba con la preparación de obreros y de profesionales en torno a unas formas de hacer y actuar requeridas para la realización de ciertos oficios y el ejercicio de determinadas disciplinas. A partir del siglo XX, la formación se relaciona con la fundamentación de la experiencia vital a través de la inculcación de saberes, habilidades y actitudes considerados imprescindibles en el mundo social y la vida laboral.

Para Villegas (2008: 12), la formación "es la experiencia como capacidad de reflexión sobre la historia misma del sujeto. De esta manera, la formación aparece menos como un objeto definido y más como la experiencia promovida en el acto a través de hechos precisos". En cuanto constitutiva de la condición humana, la formación da cuenta de la experiencia como forma práctica del devenir del sujeto en pro del desarrollo armónico de su ser. De este modo, es en formación y por formación que la facultad del hombre por reflexionar se aprende, se ejerce y se prueba. En últimas, el ser humano "necesita de la formación para llegar a ser lo que en su devenir logra ser" (ibid:: 3).

En el ámbito educativo, Anzaldúa (2009) sostiene que la formación es un proceso que sobrepasa la incorporación de conocimientos y destrezas para dar cuenta de la conformación de modos de ser, pensar y actuar presentes en las relaciones interpersonales y las prácticas sociales para las que se prepara el individuo. Para él, formación, enseñanza y aprendizaje se complementan para consolidar los conocimientos y las sensibilidades necesarias en los procesos subjetivos presentes en el qué ser de las personas. Más concretamente, él sostiene que "la formación es un proceso de subjetivación, en el que el sujeto resignifica lo que ha sido o imagina ser, en relación con lo que imagina será, en las prácticas para las que se está formando, dándole un nuevo sentido a sus deseos, identificaciones y fantasías, con-formando-transformando una identidad" (Anzaldúa, 2009: 7).

Ahora bien, pese a toda esta riqueza y profundidad en el estudio de formación, la discusión sobre formación docente ha estado condicionada en las últimas tres décadas por políticas definidas por organizaciones supranacionales movidas por intereses económicos (Padilla, 2014). Al respecto, autores como Martínez (2011) y Díaz (2018) explican que tales organizaciones han impulsado cumbres y declaraciones que, a nivel retórico, predican desplazamientos teórico-conceptuales desde orientaciones tradicionales y racionales hacia perspectivas constructivistas y críticas. No obstante, a nivel práctico, estos organismos impulsan reformas que imponen 
mecanismos centrados en la homogeneización, la mercantilización y la certificación. ${ }^{4}$ Tales mecanismos han derivado en privatizaciones, subcontrataciones y desigualdades, las cuales configuran un estado de cosas que:

no sólo está abriendo la educación a los mercados, quebrando la concepción de la educación como derecho social que ha de ser protegido por el Estado, sino que está adecuado a la misma educación a los principios y las prácticas del mercado, convirtiendo la educación en un producto más que se compra y se vende según la ley de la demanda y de la oferta (Díaz, 2018: 15).

En este contexto, Fandiño (2017) sostiene que la formación docente tiende a hacer referencia a lineamientos que proveen a los profesores con enfoques orientados más en decirles qué y cómo hacer las cosas que en facilitarles perspectivas para construir y trasformar sus realidades socioeducativas. De este modo, la formación docente parece perpetuar la premisa de que el maestro es una figura que se forma desde y para los intereses, las necesidades y los deseos de otros. Asimismo, esta premisa tiende a movilizar sistemas formativos que desconocen o restringen las intenciones, las motivaciones y los anhelos que los maestros tanto en formación como en ejercicio poseen o construyen. En últimas, tales sistemas priorizan:

la formación de un sujeto multifuncional, con competencias generales y destrezas, que enfatiza más el saber hacer que lo que se quiere ser [... esta] lógica busca constituir un sujeto-maestro para ser evaluado, clasificado y automotivado que pueda alcanzar los estándares e indicadores con los que se mide la calidad educativa (Plata, 2018: 291).
$\mathrm{Al}$ respecto, Agudelo (2019) sostiene que este tipo de sistemas deriva en aproximaciones que: a) reproducen relaciones e ideologías verticalistas cimentadas en la vigilancia, el control y sometimiento, b) instalan concepciones funcionalistas y tecnocráticas del quehacer docente, del desempeño de los estudiantes y del propósito de las instituciones educativas, y c) subvaloran el rol y la función del maestro equiparándolo a funcionario operario, técnico ejecutor o intelectual subalterno.

En Colombia, la fuerte carga verticalista, funcionalista y subalternante del sistema de formación docente se evidencia en un lenguaje demagogo acompañado de disposiciones tecnocráticas como el decreto 2450 de 2015 (otorgar y renovar registro calificado), la resolución 2041 de 2016 (obtener, renovar y modificar el registro calificado), el decreto 1280 de 2018 (crear un sistema de aseguramiento de la calidad de la educación superior) y el decreto 1330 de 2019 (facilitar registro calificado y acreditación reglamentando modalidades y diferenciando programas). Además, es de anotar que las constantes modificaciones en la legislación sugieren no improvisación por parte del Estado, sino una estrategia para distraer a educadores de maestros mediante el cambio constante de las reglas de juego para que no reflexionen críticamente sobre la formación y no logren conformarse como instituciones críticas y autónomas (Díaz, 2018).

Para superar o al menos mitigar este estado de cosas, este artículo asume la subjetivación del maestro como nueva categoría. Asumir al maestro como sujeto implica concebirlo como un actor con identidad, conciencia y autodeterminación, capaz de "un ejercicio de poder sobre sí mismo, como actitud ética, de cuidado de sí y de los otros, con los que se da forma a un modo de vida o 'arte de la existencia' (Foucault, 2005: 60). De acuerdo con Plata (2018:

\footnotetext{
${ }^{4}$ En el contexto de la globalización y del discurso de desarrollo, los sistemas educativos se han visto obligados a adoptar, entre otras cosas, la evaluación, la certificación y la acreditación como "estrategias [...] para obtener reconocimiento, incrementar su demanda, contribuir a su rendición de cuentas y en efecto al desarrollo de los países" (Clara y Vega, 2020: 76).
} 
297), la subjetivación del maestro se puede entender como "arte de vivir en función de la desujeción, para constituirse a sí mismo como un ser distinto de lo que se nos ha dado a pensar, en orden a otra forma de pensamiento, otro modo ser y actuar". De este modo, la subjetivación del maestro busca, por una parte, visibilizar y desnaturalizar condiciones y prácticas de sujeción (lógicas y dispositivos de poder que lo definen, disciplinan y vigilan) y, por otra, potenciar y legitimar posibilidades y alternativas de desujeción (lógicas y dispositivos de poder que lo subvierten, insubordinan e impelen). En otras palabras, la subjetivación del maestro "no se trata solamente de hacer visible el funcionamiento de los dispositivos de poder por medio de los cuales el sujeto es fabricado, modelado e instituido, sino reconocer que en toda condición de sujeción siempre habrá resistencia y posibilidad de ejercer el propio poder constituyente del sujeto" (Plata, 2018: 298).

$\mathrm{Al}$ respecto, Salcedo (2017) afirma que la subjetivación del maestro es una categoría que permite entender la diversidad de formas particulares e inéditas que los docentes exhiben en sus vidas cotidianas para enfrentar deliberadamente el statu quo y trasgredir el orden establecido. Para él, en la subjetivación, los maestros "ejercen agenciamientos - movimientosque destituyen a su modo la fuerza de las relaciones de poder instituido, lo cual provoca esperanza o práctica cotidiana de arrancarle sentidos al sinsentido de la institución instituida que cuadricula, divide y masifica" (Salcedo 2017: 106). Estos agenciamientos les permiten a los maestros reorientar y reconvertir las formas de relación consigo mismo y con los demás con el propósito de co-crear maneras heterogéneas de ser y formas múltiples de realizarlas.
En este contexto trasgresor y cocreador, la postura de Zemelman (1998) resulta conveniente pues él asume al maestro como un individuo capaz de vivir la subjetivación como una forma de resistencia a la inercia del diario vivir. Esta resistencia surge de procesos críticos de cuestionamiento y búsqueda de nuevos sentidos sobre lo que son, hacen, piensan y sienten. Como resultado de este tipo de subjetivación, el maestro no sólo desarrolla sus capacidades profesionales para la autonomía, el razonamiento, el asombro y el planteamiento de horizontes de sentido, sino que también se promueve como individuo con posibilidades de proyectarse, inventarse e idearse.

De este modo, este artículo propone la subjetivación del maestro como categoría de trabajo pues define al sujeto maestro ya no desde el determinismo y la homogenización, sino que, desde la presunción de autonomía y libertad, busca dar cuenta de asuntos como alteridad, diversidad y multiplicidad. La subjetivación le permite al maestro concienciarse de lo que es, lo que hace, lo que piensa y lo que dice a la vez que legitimar sus formas particulares para construir historias, sentidos y saberes a nivel personal, colegiado y profesional. En consecuencia, se propone que la comunidad educativa comprenda al maestro como sujeto que funge como actor ético-político (ser), pedagogo-intelectual (saber), socio-jurídico (poder), histórico-cultural (historia) y estético-comunicativo (lenguaje). Esta comprensión se puede fundamentar desde revisiones teóricas y articulaciones metodológicas fundamentadas inicialmente desde temas como pedagogía crítica transformadora, descolonización epistemológica, conciencia histórica, empoderamiento, autonomía y pensamiento crítico, lenguaje y enunciación, entre otros. La figura 1 resume el giro epistémico que este artículo bosqueja. 


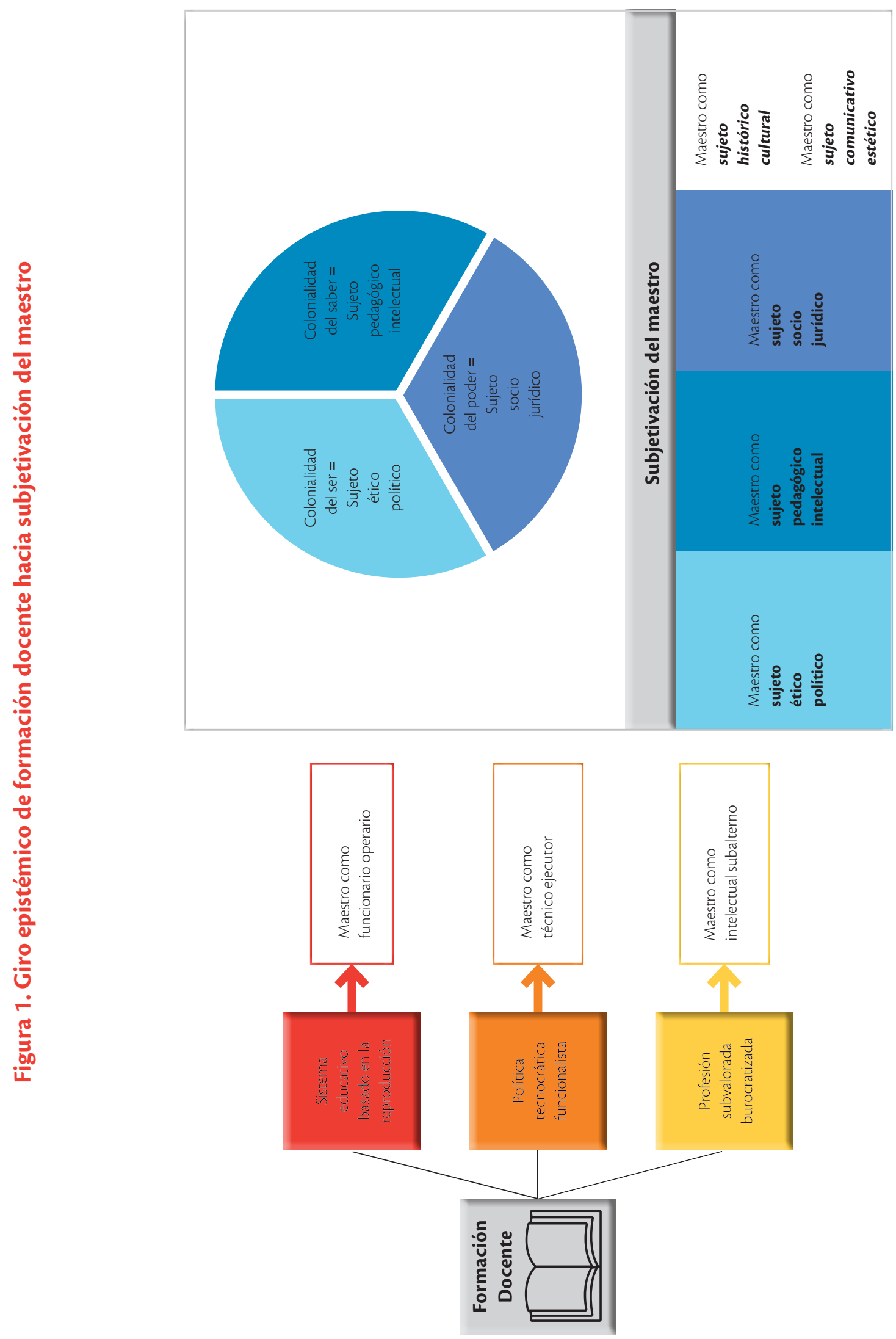


A continuación, se ofrecen algunos planteamientos iniciales sobre la subjetivación de maestros. Estos planteamientos no se proponen como lineamientos rígidos o itinerarios impositivos que se deban acatar u obedecer. Se sugieren como ejes para la reflexión pedagógica y la discusión académica de maestros, investigadores y sectores interesados en abordar el giro epistémico propuesto en este artículo. A través de diálogos transectoriales y concertaciones multiactorales, es viable infundir prácticas y discursos que eduquen al maestro como "sujeto en continuo devenir. Un sujeto que no está dado, que se reconoce en un proceso histórico y se sabe parte de una realidad siempre contingente $[\ldots]$ un sujeto que se asume en una práctica de sí inextinguible, siempre volviendo sobre sí mismo y que, a su vez, desde allí produce saber" (Herrera, 2014: 62-63).

\section{Maestros como sujetos ético-políticos}

Al hablar del maestro como sujeto ético-político, Buenfil (2010) asevera que esta perspectiva no presupone un maestro toda razón, toda bondad o toda reciprocidad ni mucho menos un ser homogéneo o prefijado. Al contrario, posibilita un maestro que acepta su finitud, liviandad ontológica, contradicción e incompletitud y, aun así, es capaz de argumentar a favor de sus acciones y decisiones. Para esta autora, el maestro como sujeto ético-político permite concebir a:

un sujeto que no se define a priori (por la razón, su posición en las relaciones de producción o cualquier otro supuesto fundamento), sino que es producto de su inserción en un mundo simbólico que le antecede y no lo determina, inserción que comprende la internalización diferencial de los valores, sensibilidades, conocimientos, disposiciones, actitudes y creencias de una comunidad (Buenfil 2010: 16).

León (2013: 121) afirma que el maestro es sujeto ético-político por excelencia, pues entra en relación con contextos y dinámicas socioculturales no simplemente habitando en ellos, sino buscando las maneras de transformarlos a través de sus acciones y saberes. De este modo, los maestros están llamados a ser "sujetos que tengan la visión de participar en la consolidación de proyectos, en la toma de decisiones y que, en su interacción con otros, conforme un colectivo que no solamente observa, sino actúa, moviliza, crea y re-crea". Por su parte, Fandiño, Carreño y Porras (2019: 96) sostienen que el maestro es un sujeto ético-político por excelencia ya que al configurar a otros se configura a sí mismo. Esta doble configuración le demanda asumirse como un actor social responsable por:

la toma de decisiones socioeducativas y la implementación de acciones ético-políticas. Estas decisiones y acciones deben permitir, entre otros aspectos, la resolución de problemas y la satisfacción de necesidades tanto personales como comunitarias a partir de ejercicios individuales y colectivos de diálogo, participación, reflexión y acción.

En este artículo, se asume al maestro como sujeto ético-político inicialmente desde el empoderamiento, la autonomía y el pensamiento crítico.

\section{Empoderamiento y autonomía del maestro}

De acuerdo con Asunción (2019), el empoderamiento del maestro es un proceso que le permite problematizar su saber pedagógico para adueñarse de su práctica y mejorar su realidad. Para tal fin, el maestro desarrolla actitudes como líder e investigador, las cuales lo equipan para innovar su praxis y reconstruir su realidad. Como resultado, el maestro se ve abocado a ser un actor que:

cuestione y analice los fundamentos y procesos de donde se derivan los conocimientos sobre la enseñanza, que reconozca las distintas formas de argumentación y privilegie la vida misma del que aprende, 
favoreciendo la aparición de diversas racionalidades contextualizadas y que cambie su relación al conocimiento de su profesión (Asunción 2019: 11).

Para Pascual (2019), el empoderamiento del maestro va de la mano de estrategias que amplían sus probabilidades para gobernar sus propias acciones. No obstante, él explica que la promoción y el logro de cambios frente a circunstancias que afectan las dinámicas o los entornos de grupos o instituciones requieren el desarrollo sociocomunitario de un conjunto de recursos para satisfacer necesidades u obtener aspiraciones. El desarrollo de dichos recursos conlleva la asunción de dos perspectivas: la perspectiva socioestructural (escrutar las relaciones de poder presentes en las estructuras y las culturas organizacionales, las cuales condicionan el empoderamiento del maestro) y la perspectiva sicológica (indagar los rasgos individuales y colectivos que se necesitan para que el maestro y sus grupos colegiados tomen conciencia, emprendan cambios y transformen contextos y dinámicas).

Ahora bien, el empoderamiento del maestro exige autonomía. Al respecto, Contreras (2006) alerta que este concepto ha estado relacionado con un sentido individualista y racionalista de la conducta y la actuación propia. Para superar este individualismo y enfatizar la naturaleza relacional de la tarea educativa, él comprende la autonomía como una tarea de correspondencia que posibilita el crecimiento mediante la búsqueda del reconocimiento del y el entendimiento con el otro. En consecuencia, sostiene que la autonomía del maestro:

tiene que ver con las experiencias y las prácticas de relación, mediación y convivencia que sostienen las dimensiones básicas del vivir y convivir [...] lo que busca es siempre una dimensión y una posibilidad nueva a las relaciones, que para hacer posible la convivencia y la libertad no se haga dependiente de una imposición por el poder, por las normas, por la legalidad. [Autonomía] que sólo se hace en relación con el otro (incluso a veces en relación de conflicto, pero no denegación) (Contreras 2006: 243).

En 2008, Lenis sostiene que la autonomía del maestro redimensiona las prácticas pedagógicas puesto que rescata dos acciones centrales para el éxito de la enseñanza: tomar decisiones y pensar por sí mismo. No obstante, señala Lenis que la toma de decisiones y el pensamiento del maestro se ven influidos por tres instancias: 1) instancias regulativa-normativas que se dan en los juegos de roles y poder propios de la estructura organizativa del sistema educativo, 2) instancias prácticas que condicionan las acciones y decisiones presentes en el quehacer pedagógico y 3) instancias vitales que rodean las experiencias y los itinerarios posibles en el desarrollo profesional. Por su parte, Osses (2016) sostiene que la autonomía del maestro no es una capacidad o un estado que se logre de una vez y para siempre. Por el contrario, está en construcción constantemente moviéndose entre una heteronomía anclada en las pautas morales del sistema educativo y una autonomía verdadera impulsada por proyectos conscientes y personales en la institución educativa.

\section{Pensamiento crítico del maestro}

Para Boisvert (2004: 25), el pensamiento crítico se define como "las capacidades y las actitudes que desempeñan un papel principal en el proyecto de analizar y dominar las innumerables informaciones que caracterizan el contexto social actual". Dicho análisis y dominio implica la apropiación de destrezas que les posibiliten a las personas entender estratégicamente la vida social, académica, laboral, personal, etcétera. El pensamiento crítico no está, entonces, atado a la educación y la ciencia mediante la lógica y la reflexión, sino que hace parte de la vida diaria a través de la perspicacia y el ingenio. El pensamiento crítico permite activar y aplicar tanto la inteligencia lógico-científica como la inteligencia socioemocional 
para comprender o transformar la realidad y tomar decisiones y acciones estratégicas.

En este contexto, el pensamiento crítico del maestro implica su compromiso con educar para la vida con el propósito de viabilizar acciones transformadoras tanto en su vida académica, profesional y personal como en la de sus estudiantes. Tal compromiso lleva al maestro a guiar su práctica pedagógica hacia la enseñanza de habilidades de pensamiento de orden superior y el trabajo con resolución de problemas e innovación creativa. Igualmente, este compromiso conlleva un deber social y una acción crítica que deriven en un proceso educativo en el que se trabajen los diferentes niveles del potencial mental de los estudiantes y se articulen diversas estrategias pedagógicas (ver Bezanilla, Poblete, Fernández, Arranz y Campo, 2018).

\section{Maestros como sujetos pedagógico-intelectuales}

La pedagogía y el intelecto son claves en la subjetivación de los profesores, ya que les permiten comportarse y actuar como actores emancipados, dotados con conciencia plena y capacidad para acciones autónomas. Desde esta perspectiva, la subjetivación de los maestros es un proceso de construcción pedagógica e intelectual a través del cual ellos reinterpretan y transforman su ser, sus acciones y sus pensamientos (Zemelman y León, 1997). Siguiendo esta línea de pensamiento, Loaiza (2018) sostiene que los maestros deben concebir la pedagogía como el eje que articula toda la teoría y la práctica docente. Esto es así porque la pedagogía fundamenta y moviliza prácticas metodológicas y curriculares como la lectura del contexto, el discernimiento del estudiante, la selección del método, la organización de la clase, la preparación de recursos y el seguimiento al progreso de los estudiantes.

Por su parte, Giroux (2017) explica que los maestros deben ser asumidos y asumirse como individuos libres con una dedicación especial a los valores de la inteligencia y al aumento de la capacidad crítica de las personas. Como intelectuales, los maestros deben considerar los intereses ideológicos y políticos que estructuran la naturaleza del discurso, las relaciones sociales del aula y los valores que legitiman su enseñanza. En este artículo, se asume a los profesores como sujetos pedagógicos-intelectuales adoptando premisas de la pedagogía crítica transformadora y la descolonización epistemológica.

\section{Pedagogía critica transformadora}

En contravía de una visión de los maestros como funcionarios, técnicos y subalternos encargados de la formación de mano de obra calificada, la pedagogía crítica transformadora los asume como actores de prácticas liberadoras que buscan educar hombres nuevos, conscientes de sus realidades y comprometidos con su trasformación. Para Sánchez et al. (2017: 42), esta pedagogía busca, entre otras cosas, que los maestros sepan y puedan "1) desarrollar condiciones en las que se puedan leer y escribir dentro y en contra de los códigos culturales existentes, y 2) crear espacios para producir nuevas formas de conocimiento, subjetividad e identidad". Para tal fin, ellos deben estar comprometidos con una reflexión y una investigación que desentrañen los intereses ideológicos y políticos en la escuela, revelen la naturaleza subrepticia del discurso educativo, desnaturalicen las relaciones autoritarias en el aula y cuestionen valores que la enseñanza institucionalizada normaliza.

Al respecto, Rojas y Gualteros (2018) sostienen que la pedagogía crítico-emancipadora les solicita a los maestros trabajar con cinco procesos diferentes pero relacionados: la emancipación, la liberación, la concienciación, la alteridad y la negociación intercultural. La emancipación significa facultad del sujeto para construir su razón crítica a través de su capacidad de autorreflexión, la cual no es aislada, sino socialmente intencionada e intersubjetiva. Gracias a la emancipación, la liberación toma lugar como la superación de "cualquier condición de dominación 
y opresión; al mismo tiempo, aquello alcanzado propone formas de organización más comunitarias, en donde las relaciones sociales, instituciones, acciones y discursos problematizan la existencia humana" (Rojas y Gualteros 2018: 82). Al problematizar la realidad y optar por opciones de cambio y de acción, el maestro asume un ejercicio de concienciación, el cual acontece como "un movimiento intersubjetivo de la formación de un sujeto epistémico-social situado, que mira y valora lo original de su territorio, que se apropia de él y lo transforma como posibilidad de vida más digna y de mejor calidad" (ibid.: 87). De este ejercicio de concienciación, los maestros comprender el valor de la alteridad y de la negociación intercultural. La primera es "un proyecto emergente desde lo periférico, representado por los sujetos oprimidos y explotados, en el cual la búsqueda y determinación de aquel otro tiene como propósito principal transformar la realidad de las relaciones por fuera de la jerarquía totalizante" (ibid.: 72), mientras que la segunda es "un proceso dinámico de negociación social que, a partir de una realidad fuertemente marcada por el conflicto y las relaciones sociales asimétricas, busca construir relaciones más justas entre los actores sociales pertenecientes a universos culturales diferentes, sobre la base del reconocimiento a su diversidad" (ibid.: 91).

\section{Descolonización epistemológica}

En oposición a lógicas coloniales de la producción de conocimiento, el Sur Global ha movilizado discursos contrahegemónicos que, entre otras cosas, cuestionan el eurocentrismo, reclaman nuevos tipos de conocimientos, objetan las estructuras de dominio, reivindican las culturas subalternas y promueven el poder popular. Para De Sousa Santos (2011: 14), dichos discursos hacen partes de las epistemologías del Sur, las cuales tienen como elemento constitutivo "la posibilidad de reconstruir, formular y legitimar alternativas para una sociedad justa y libre". Por ende, las epistemologías del Sur cuestionan que "el presente sistema-mundo moderno-colonial privilegie, a nivel epistémico y a nivel de la economía-política, un mundo uni-versal en detrimento de un mundo pluriversal" (Lamus, 2007: 327). Para Mignolo (2010), tal cuestionamiento exige la deslegitimación de la matriz colonial caracterizada por una colonialidad (cosmovisión eurocéntrica) del poder (mecanismos y lógicas de gobernabilidad, clasificación social y dominio), el saber (parámetros y procesos de construcción de conocimiento ligados a una racionalidad occidental) y el ser (ontología dominante que circunscribe nociones como la subjetividad, el género y la sexualidad).

En este contexto de descolonialización epistemológica, Panotto et al. (2020) argumentan que los maestros deben insubordinar dos frentes fundamentales: el lugar del intelectual en la investigación y el lugar de la propia institucionalidad académica. En el primer reto, los maestros procuran transgredir los códigos y métodos que emplean en su trabajo intelectual con el fin de legitimar saberes y narrativas locales que disloquen concepciones impuestas por la lógica del poder colonial. En relación con la institucionalidad académica, los maestros pretenden transformar la escuela y la universidad para alejarse de prácticas institucionalizadas en mercados, en la elaboración de prescripciones propia de una mercantilización del conocimiento y una instrumentalización de la producción académica. A partir de la insubordinación de los retos y frentes descritos anteriormente, los maestros pueden replantear no sólo sus puntos de partida epistemológicos sino también hacer realidad:

cambios concretos a nivel institucional que involucren diseños curriculares más flexibles y plurales (y no atenidos a los típicos campos disciplinares europeos), producción académica diversificada (es decir, no sólo a través de papers en revistas indexadas sino desde otro tipo de producciones que involucren el arte, la narrativa, lo visual, etc.) y dinámicas pedagógicas críticas que incluyan los factores sociopolíticos 
y culturales en cualquier abordaje, desde un espacio de diálogo abierto e intercultural (Panotto et al., 2020: 217)

\section{Maestros como sujetos socio-jurídicos}

Hablar del maestro como sujeto socio-jurídico implica reflexionar sobre procesos sociales de interiorización y exteriorización, así como prácticas jurídicas de sujeción y subjetivación presentes en la imbricación de tres espacialidades en las que se movilizan los educadores: Estado-Escuela-Comunidad. Dichos procesos y prácticas dan cuenta de la interrelación socio-jurídica entre dinámicas que se entretejen cuando el maestro actúa como servidor público (Estado), pedagogo investigador (Escuela) y agente sociocomunitario (Comunidad). Tal interrelación exige considerar asuntos derivados de la intervención de maestros al establecer relaciones interpersonales y experimentar situaciones de convivencia en sus comunidades, y al responder reglamentariamente ante obligaciones pactadas y cumplimientos requeridos en sus instituciones educativas.

Al reflexionar sobre la capacidad creativa de los sujetos para relacionarse socio-jurídicamente con dinámicas convenidas, realidades asignadas y normas impuestas, García (2009: 213) compele a los sujetos a movilizar técnicas del sí mismo para la construcción de "un diálogo permanente entre las partes que lo constituyen; la forma en que se relacionan con las reglas y valores propuestos socialmente; la manera en que se someten a un principio de conducta, que obedecen o resisten a una prescripción o prohibición. Por su parte, Hernández y Toro (2017: 37) sostiene que el cuidado de sí mismo está vinculado a:

la búsqueda del sujeto por [...] una verdad sobre sí mismo, fruto de la contemplación, hacer de la vida una obra de arte, es vivir en consecuencia con lo que se piensa, aunque a veces represente ir en contra de lo establecido, del sentir de la mayoría, de las verdades que, por ser compartidas por la ciencia, se hacen verdades absolutas; no es solamente interrogarse el devenir del sujeto, sino el devenir de la época.

Preliminarmente, se apuesta por asumir al maestro como sujeto socio-jurídico tanto desde la conciencia social y la acción colectiva como desde la dignificación del estatuto del maestro y el colectivo magisterial.

\section{Conciencia social y acción colectiva}

Como sujetos socio-jurídicos, los maestros cuentan con una capacidad para reflexionar y comprender el estado de sí mismos y de otros dentro de la sociedad. A esta capacidad, Vallejo (2020: 35) la llama conciencia social, entendiéndola como un entendimiento construido "sobre la base de una identidad colectiva, la cual se forma a partir de la conciencia social del individuo". De este modo, el maestro es capaz de diseñar y ejecutar una serie de acciones colectivas encaminadas a la modificación de modos de pensar y actuar de individuos a la vez que a la transformación de dinámicas y sinergias grupales. Estas acciones, además, implican "la afirmación efectiva de la pertenencia a colectividades, lo cual lleva a los sujetos a asumir un papel activo en las decisiones de sus comunidades humanas, teniendo como fundamento la autonomía de sus propios planes de vida" (Celemin, Martínez, Vargas, Bedoya y Ángel, 2006: $6)$.

A partir de la consolidación de la conciencia social, los maestros tienen la posibilidad de llevar a cabo manifestaciones organizadas de interacción colegiada para lograr objetivos comunes. Dichas manifestaciones interactivas hacen parte de lo que Vallejo (2020: 68) llama acción social, la cual les permite a los individuos y sus colectividades dar origen a movimientos sociales. Estos movimientos les permiten "empoderarse y poner en manifiesto dicho poder cuando deciden trabajar en conjunto y unir sus fuerzas para enfrentarse a sus antagonistas sociales". Para Medina (2018: 172), los movimientos 
sociales dan cuenta de acciones y relaciones sociales que constituyen "un campo de fuerzas que se produce estableciendo sentidos, prácticas, actores-sujetos, epistemes-saberes-conocimientos a través de dispositivos y materialidades. Se expresa en formas de inducción, reconfiguración de sentidos, modelos y representaciones del ejercicio de prácticas sociales". ${ }^{5}$

\section{Dignificación del estatuto del maestro y el colectivo magisterial}

Como sujetos socio-jurídicos, los maestros enfrentan un complejo entramado de definiciones de ley, reformas educativas y exigencias económico-administrativas. Al respecto, Méndez (2014: 68) mantiene que "En este intrincado laberinto, intentar definir quién es el maestro hoy, y de qué estatuto goza, implica develar múltiples escenarios y distintas fuerzas que se superponen, coexisten y se solapan en la configuración de su situación actual". Tal develamiento conlleva comprender cómo los intereses de ciertas fuerzas han marcado históricamente, entre otras cosas, el rol y la imagen del maestro, la promoción social de su labor, los niveles de respeto y confianza en su quehacer y las condiciones de su trabajo. Para Martínez Boom (2008: 59), este develamiento implica analizar genealógicamente el devenir del estatuto del maestro para dar cuenta de un devenir con zozobras y tensiones ante el cual el maestro "no puede seguir reconociéndose en imágenes que la sociedad, el poder y la cultura le ofrecen; todo lo contrario, cada vez es más imperiosa una actitud de acecho, en donde brille su autenticidad, su potencia y su resistencia". ${ }^{6}$
En la actualidad, la imagen del educador da cuenta de la existencia de unas lógicas neoliberales, mercantilistas y despedagogizantes que constriñen al maestro mediante reglamentos, escalafones, evaluaciones y contrataciones. Para González (2019), este constreñimiento pretende perpetuar una episteme colonial aferrada a la dominación ideológica y el control discursivo mediante un sistema educativo burocrático, tecnocrático y funcionalista. En contraposición de este estado de sujeción y dominación, González exhorta a una dignificación de la labor del maestro y del colectivo magisterial que permita, entre otras cosas, trascender la racionalidad instrumental, cuestionar la fabricación de individuos competentes, trasgredir la legislación privatizadora de la educación como servicio e indisciplinar la homogeneización del deber ser mediante estándares, competencias y logros.

Arias et al. (2014: 66) describen la dignificación de la labor docente y el colectivo magisterial como "la búsqueda constante de autenticidad e independencia, lo cual implica experiencias permanentes de respeto y libertad dentro y fuera de la escuela". Entre otras cosas, esta búsqueda implica la generación de vivencias de independencia para entender el contexto, reconocer al otro como un par igual y actuar como un actor real en lo social, político y cultural. Por su parte, Amaya et al. (2014) sostienen que la dignificación del colectivo magisterial exige, además de reconocimiento social, estatus profesional y calidad de vida, el aseguramiento de condiciones laborales, ambientes de trabajo y tratos humanos que favorezcan un sentido de decoro y satisfacción con lo que se es, se conoce y se hace.

\footnotetext{
${ }^{5}$ En nuestro continente, la conciencia social y la acción colectiva de los maestros como sujetos socio-jurídicos han dado pie a movimientos pedagógicos que, además de suscitar discusiones ideológicas sobre el rol del maestro y su estatus como sujeto, potencian la organización de una conciencia de sí, al implicar "una introspección, que permita constituir un modo de vida a través de herramientas que faciliten el autocuidado, la autorreflexión, en busca de una transformación y cambio constante, en otras palabras, aplicar las tecnologías del yo" (González y Tibaduiza, 2015: 31).

${ }^{6}$ Rodríguez (1998) discute la presencia de tres rostros o imágenes del maestro: abnegado apóstol, funcionario estatal y trabajador de la cultura. El primer rostro da cuenta de una herencia judeo-cristina que asume el magisterio con un sacerdocio. El segundo rostro da indicios de la judicialización del saber del maestro mediante una preocupación por el método y el currículo y un asalaramiento de acciones, tiempos y espacios. El tercer rostro sugiere unos quiebres y unas tensiones con los anteriores rostros para posibilitar transformaciones en los discursos y las prácticas mediante movimientos y propuestas alternativos.
} 


\section{Maestros como sujetos histórico-culturales}

El asumir al maestro como sujeto histórico-cultural conlleva buscar el origen y el sentido de las nociones y los fenómenos pedagógico-educativos a partir de su invención e instauración. Para Villegas (2014), esta búsqueda es un proceso de realización individual al igual que uno de construcción social a través del cual el sujeto maestro apropia modos históricoculturales y formas teórico-prácticas pertinentes para sus instituciones educativas. Es una aproximación a la subjetivación del maestro que proporciona claves explicativas, las cuales permiten entender tanto la construcción del quehacer del maestro como la fundamentación de cánones profesionales.

Para Saldarriaga y Vargas (2015: 314), la asunción del maestro como sujeto histórico-cultural permite entender, entre otras cosas, como él ha pasado de "autorepresentarse como un sujeto social oprimido entre otros, a reconocerse como un trabajador intelectual o de la cultura, que ha sido relegado a la condición de subalternidad intelectual por un régimen (epistemológico-político) de saber". Tal reconocimiento posibilita legitimar la sociohistoricidad del maestro cuya presencia y voz se ha movido entre una dependencia paternalista de las autoridades y un activismo intelectual frente a las esferas de poder-saber-ser. Inicialmente, se propone asumir al maestro como sujeto histórico-cultural desde su conciencia histórica y memoria colectiva, y su capacidad para la acción y el cambio cultural.

\section{Conciencia histórica y memoria colectiva}

Como sujetos histórico-culturales, los maestros están llamados no sólo a tener conciencia y memoria de su historia personal y colectiva, sino a hacer historia; es decir, construir y deconstruir su historia al convertirse en sujetos que contextualizan e interpretan sus devenires y porvenires. Para llevar a cabo dicha contextualización, los maestros necesitan adquirir y desarrollar conciencia histórica. Para Pantoja et al. (2013: 142), esta categoría "no sólo examina el cómo los sujetos observan el pasado, sino también los acuerdos individuales y colectivos del pasado, los factores cognitivos y culturales que dan forma a éstos, así como las relaciones de acuerdos históricos con los del presente y el futuro". Es un esfuerzo consciente y sistemático por juzgar por sí mismo el valor de las continuidades y discontinuidades, resolver preguntas esenciales sobre presente-pasado-futuro y reconocer el propio papel creativo dentro de la historia. Como resultado de este esfuerzo, la conciencia histórica es "un proceso de comprensión dialéctica con el presente, pero no en aras de sí mismo, sino en la construcción mental y material de alternativas de futuros críticos que lleven por diferentes caminos" (ibid.: 139).

Por su parte, Miguel-Revilla y Sánchez-Agustí (2018: 117) hablan de la posibilidad de construir una memoria colectiva que sirve de orientación para "una búsqueda por la cohesión y la continuidad en un objetivo simbolizador capaz de dar sentido al pasado y al propio presente". La construcción de esta memoria colectiva va de la mano de la historización, entendida como un proceso en el cual los sujetos dotan de sentidos particulares al trascurrir del tiempo a través de la experiencia. Más concretamente, la historización es "un hecho subjetivo, un fenómeno de conciencia adquirida, una autorreflexión desde el ángulo temporal sobre la experiencia misma y la interpretación de su significado, que conduce a un entendimiento particular de la temporalidad" (Aróstegui, 2004, en Miguel-Revilla y Sánchez-Agustí, 2018: 115).

\section{Acción y cambio cultural}

Los procesos de relación, comunicación y convivencia con estudiantes, colegas, instituciones y entornos se dan en medio de la triada escuela-familia-comunidad. Para Barberousse-Alfonso et al. (2018: 8), esta triada configura un espacio de interacción transgeneracional, pluridimensional y multiactoral, en el cual los maestros experimentan "diversos procesos 
de formación, resultado de acuerdos colectivos entre todos los miembros que interaccionan desde la heterogeneidad cultural $[\ldots]$ produciendo encuentros que permiten asentar una cultura de solidaridad entre todos los agentes y agencias que participan". Esta diversidad de procesos formativos les exige a los maestros movilizar "modos de saber, hacer y ser que habiliten la construcción de estructuras dadoras de sentido compartido, sentido común, sentido comunitario" (Dabezies, 2013: 3).

La construcción de sentidos compartidos hace que los maestros se constituyan como agentes de acción y cambio cultural. García López (2010: 3) entiende al agente de acción-cambio como aquel que es capaz de:

desarrollar en una institución, acciones, actitudes y procesos que permitan realizar mejoras proactivamente en los diversos aspectos internos y externos [...] sabe crear un clima favorable de cambio dentro de su equipo de trabajo y la organización de manera que las personas no sean sólo [agentes], sino protagonistas y [actores] colaboradores de él en el proceso de cambio.

Para García (2015), los maestros, además de desear la acción-cambio, deben construirla con voces propias y acciones nuevas, siendo conscientes de que ésta no puede ser superficial o temporal, sino profunda y duradera. Por ende, la acción-cambio les plantea a los maestros alternativas para su desarrollo personal, imagen profesional y liderazgo escolar mediante comunidades de aprendizaje que intercambien experiencias, reflexionen sobre la práctica e indaguen por dinámicas transgresoras. $\mathrm{Al}$ respecto, Estivalis et al. (2016: 15) sostienen que estas nuevas lógicas deben permitirles a los maestros trasformaciones e innovaciones sociales, institucionales y culturales mediante el diseño y la implementación de "estrategias de análisis colectivo y de reconocimiento comunitario, modos de actuación concretos, espacios de desarrollo asociativo y dinámicas de vinculación escuela-territorio".

\section{Maestros como sujetos estético-comunicativos}

Asumir la estética y la comunicación como piedras fundantes del sujeto maestro posibilita alejarse de miradas instrumentalistas y antropocentristas de su ser y quehacer para acercarse a perspectivas dinámicas y complejas. Ya desde el año 2000, Martín-Barbero aseguraba que hablar de comunicación implica reconocer que se está en una sociedad del conocimiento y la información. En este estado de cosas, dos dinámicas impulsan cambios que el sujeto maestro debe conocer: a) la aparición de un ecosistema comunicativo tanto con sensibilidades nuevas como con empatías cognitivas y expresivas y b) un entorno de información y saberes múltiples, difuso y descentrado. Frente a este sensorium nuevo y estos saberes-mosaico, el maestro como sujeto estético-comunicativo debe contar con conocimientos, habilidades y actitudes que enseñen al estudiante a "tener acceso a la multiplicidad de escrituras, de lenguajes y discursos en los que se producen las decisiones que lo afectan ya sea en el plano laboral o familiar o en el político y el económico" (Martín-Barbero, 2000: 40).

Para Romeu y Piñón (2014), comprender la dimensión estético-comunicativa tiene su anclaje en el hecho de que el sujeto maestro es un enunciador e interlocutor por excelencia, cuyo ser, hacer, pensar y sentir interactúa con medios y mediaciones con los cuales lleva a cabo producción e interpretación de significados y sentidos. Por su parte, Giraldo y Maya (2015) sostienen que estos nuevos modos de existir, actuar, conocer y sentir circulan en ecosistemas de naturaleza plurívoca y polisémica caracterizados por un complejo entramado de procesos y prácticas históricos, simbólicos, intersubjetivos, multimodales y multimediáticos. En este artículo, se asume al maestro como sujeto comunicativo-estético desde el lenguaje y la enunciación y la literacidad, la multimodalidad y la multialfabetización. 


\section{Lenguaje y enunciación}

Gutiérrez (2012) señala que el lenguaje acontece en situaciones de interacción en las cuales se producen relaciones de poder simbólico entre individuos y grupos. En medio de estas relaciones de poder, cierto orden social se naturaliza y cierta distribución del capital cultural se legitima. Además, estas relaciones de poder posibilitan ciertas prácticas comunicativodiscursivas y establecen ciertos modos de producción de conocimiento. De este modo, el lenguaje y la competencia comunicativo-discursiva se constituyen en objetos de interés para los maestros, pues la adquisición y el desarrollo de las capacidades para lenguajear y discursar entran en un campo de interacción que determina tanto las posibilidades que tienen los sujetos para expresarse y ser atendidos como las alternativas a las que pueden recurrir para resistir textos dominantes y subvertir sentidos impuestos.

Para Muñiz (2018), es importante deconstruir el campo de interacción en el cual se actualiza el lenguaje como discurso para considerar las fuentes estructurales y la intencionalidad en la producción de significados y sentidos. Tal deconstrucción exige la identificación del espacio epistémico desde el cual se crea y se comunica, es decir, el lugar de enunciación. Este lugar no es un espacio físico en el contexto, sino una categoría analítica que permite reconocer el espacio epistémico que el autor habita y desde el cual realiza la interpretación de sentido (compresión hermenéutica). De este modo, los maestros deben asumir el lugar de enunciación como "un espacio epistémico desde el cual se articula el horizonte de interpretación, el cual nos remite a la base del sistema cultural que se expresa por medio de un discurso individual" (Muñiz, 2018: 25).

\section{Literacidad, multimodalidad y multialfabetización}

La literacidad es un constructo teórico complejo que abarca desde la enseñanza-aprendizaje del código escrito hasta las habilidades de razonamiento asociadas con las prácticas lecto-escriturales. Retomando a Cassany (2006), Londoño (2014: 199) sostiene que la literacidad da cuenta de "la interacción de un sujeto crítico con respecto a las diferentes prácticas discursivas, las cuales no sólo son el producto del conocimiento (campo disciplinario) sino que tienen un carácter sociocultural, donde el mismo conocimiento se ve afectado por ese contexto". Al respecto, Riquelme y Quintero (2017) explican que, más allá de la llamada alfabetización funcional (saber hacer uso de habilidades lecto-escriturales en el mundo laboral y social), la literacidad es una práctica social, situada históricamente y aplicada culturalmente.

A partir de Mignolo (2003), Fraga (2015) sostiene que la literacidad asume la comunicación humana como una interacción semiótica mediada por signos y respaldada por grupos sociales. Para Fara, los maestros deben entender que estos signos no se refieren únicamente a la escritura alfabética promovida desde el occidente moderno, sino que incluyen cualquier escritura simbólica o figurativa que permite diálogos e intercambios. Ahora bien, el desarrollo tecnológico y comunicativo del siglo XXI pone la literacidad en perspectiva. Esto es así porque las personas hoy participan en entornos en los que leen y crean textos que a menudo son una combinación de textos, fotografías, imágenes en movimiento y con sonido creados a través de teléfonos celulares, tabletas o computadores portátiles. Estas nuevas formas de crear, consumir y mediar significados es llamada multimodalidad por autores como Magnusson y Godhe (2019). Para Farías y Véliz (2019), textos que combinan más de un modo (auditivo, visual, gesticular, espacial, etcétera) y una modalidad (escrita, leída, hablada, proyectada, etcétera) para comunicar significado, son cada vez tan comunes como los documentos impresos. Por otra parte, las prácticas multimodales de los estudiantes son cada vez más dinámicas, interactivas y ubicuas. Como resultado, el maestro debe movilizarse hacia una multialfabetización que dimensione el leer y el escribir en contextos semióticos y tecnológicos complejos. 
$\mathrm{Al}$ respecto, Taylor (2012) explica que el siglo XXI exige multialfabetización, la cual comprende la recepción, la comprensión y la producción de procesos multimodales que incluyen la lectura de textos impresos y electrónicos al igual que el uso de representaciones visuales, espaciales, gestuales y auditivas. Para este autor, el término multialfabetización funciona como una noción expandida y expansiva del texto y lo que significa estar alfabetizado. En este contexto, New London Group (2000: 9) proclamó que los maestros deben saber y poder: "ampliar la idea y el alcance de la alfabetización para dar cuenta del contexto cultural y lingüísticamente diverso de sociedades cada vez más globalizadas; para dar cuenta de las múltiples culturas que se interrelacionan y la pluralidad de textos que circulan".

\section{Conclusiones}

Este artículo ha invitado a la comunidad educativa a asumir, en lugar de formación docente, la subjetivación del maestro mediante un giro epistémico. Inicialmente, esta asunción conlleva criticar la presencia de perspectivas funcionalistas, tecnocráticas y eficientistas que limitan políticas y lineamientos a la vez que desfiguran reformas educativas y proyectos curriculares. Principalmente, esta asunción busca movilizar discursos y procesos que desnaturalicen la existencia de un maestro asumido como simple funcionario y técnico del sistema educativo. Un operario pasivo en el acto educativo a quien se le indica qué enseñar y cómo actuar, lo que desdibuja su naturaleza y limita sus posibilidades en pro de la satisfacción de los intereses y las necesidades de agendas y organismos internacionales (Berrio y Jaramillo, 2012).
Para que tal giro epistémico sea posible, se propuso comprender la subjetivación del maestro como la configuración de un actor de esencia múltiple: sujeto ético-político, pedagógico-intelectual, sujeto sociojurídico, sujeto histórico-cultural y sujeto estéticocomunicativo. Esta configuración implica reconocer las posibilidades que tiene el maestro de ejercer poder constituyente sobre dimensiones diferentes pero complementarias de sí mismo. Este poder constituyente le permite al maestro no sólo sensibilizarse sobre condiciones de sujeción o lógicas de control que buscan instituirlo y modelarlo, sino concienciarse sobre resistencias creadoras, agenciamientos colectivos e iniciativas propositivas que le permiten re-pensarse y re-crearse. Dicha concienciación se viabiliza al "praxizar"7 asuntos como pedagogía crítica transformadora, descolonización epistemológica, conciencia histórica, memoria colectiva, acción y cambio cultural, los cuales posibilitan materializar devenires alternativos, trayectos de fuga y prácticas de resistencia.

Finalmente, se busca que la subjetivación del maestro permita reconfigurar la comunidad educativa, sus discursos pedagógicos y sus proyectos curriculares. Tal reconfiguración exige nuevos modos de conocer, ser y hacer que van de la formación de un docente fijo y predeterminado hacia la educación de un maestro transgresor y mutable. En últimas, esta reconfiguración puede impulsar a la comunidad educativa y a los maestros mismos a "romper con los usos e inercias arraigados y superar el marco de racionalidad ya rebasado para adaptarse a un mundo dinámico, inmerso en profundos procesos de transformación" (Mendoza, 2018: 62).

\footnotetext{
${ }^{7}$ En 2009, Sharkey propone el término "praxizar" para referirse al proceso de desafiar los conceptos y los principios que nos son presentados como verdades y certezas mediante el uso de herramientas de cuestionamiento intelectual que permiten examinar nuestros contextos, identificar desafíos y cuestionar asunciones subyacentes con el propósito de producir teoría-práctica desde nuestras propias realidades.
} 


\section{Referencias}

Agudelo, Diana (2019), "Lectura crítica de la formación de docentes y las políticas públicas en educación en Colombia", Revista Electrónica: Entrevista Académica, vol. 1, núm. 4, pp. 281-304.

Amaya, Ever, Ángela Delgado, Luz Gnecco, Eudosia León y Diana Valencia (2014), "Creencias de un grupo de profesores sobre condiciones laborales que dignifican y precarizan su profesión”, Tesis de maestría, Bogotá, Universidad San Buenaventura, <http://biblioteca. usbbog.edu.co:8080/Biblioteca/BDigital/83580.pdf> [Consulta: junio de 2021].

Anzaldúa, Raúl (2009), "La formación: una mirada desde el sujeto", X Congreso de investigación educativa, Consejo Mexicano de Investigación Educativa(COMIE), <http:// www.comie.org.mx/congreso/memoriaelectronica/v10/ pdf/area_tematica_15/ponencias/0251-F.pdf>.

Arias, Flor, Isabel Jiménez, María Matallana, Sonia Matallana, Mayerly García, Hernán Alonso, Juan Gómez y Giovanni Salazar (2014), "Conceptos de dignificación del maestro: lectura desde su hacer en la escuela", Pensamiento educativo, vol. 1, núm. 1, pp. 63-68, <https://www.usbbog.edu.co/images/pdf/ pensamiento_educativo_seriado_N.1.pdf> [Consulta: junio de 2021].

Asunción, Suniaga (2019), "Metodologías activas: herramientas para el empoderamiento docente", Revista Internacional Docentes 2.0 Tecnológica Educativa, vol. 19, núm. 1, pp. 1-16.

Barberousse-Alfonso, Paulette, Marie Vargas-Dengo y Pamela Corrales-Bastos (2018), "Formación docente inicial y acción socioeducativa: construyendo una propuesta de implementación del Programa Maestros Comunitarios (PMC)", Revista Electrónica Educare, vol. 22, núm. 1, pp. 1-21.

Beillerot, Jacky (1998), La formación de formadores (entre la teoría y la práctica), Argentina, Ediciones Novedades Educativas.

Berbaum, Jean, Maurice Debesse y Gaston Mialaret (1982), La formación de los enseñantes, Cádiz, Oikos Tau Ediciones.
Berrio, Isabel y Alexandra Jaramillo (2012), "Prácticas de subjetivación y subalternización del maestro", Tesis de pregrado, Antioquia, Licenciatura en Ciencias Sociales, Facultad de Educación, Universidad de Antioquia.

Bezanilla, María José, Manuel Poblete, Donna Fernández, Sonia Arranz y Lucía Campo (2018), "El pensamiento crítico desde la perspectiva de los docentes universitarios", Estudios Pedagógicos, vol. 64, núm. 1, pp. 89-113.

Boisvert, Jacques (2004), La formación del pensamiento crítico. Teoría y práctica, México, Fondo de Cultura Económica.

Buckley, Roger y Jim Caple (1991), La formación: teoría y práctica, Madrid, Ediciones Díaz de Santos.

Buenfil, Rosa (2010), "Dimensiones ético-políticas en educación desde el análisis político de discurso", Sinéctica, núm. 35, pp. 1-17.

Calvo, Gloria, Diego Rendón y Luis Rojas (2004), "Un diagnóstico de la formación docente en Colombia", Revista Colombiana de Educación, núm. 47, pp. 1-15.

Cassany, Daniel. (2006), Tras las líneas. Sobre lectura contemporánea, Barcelona, Editorial Anagrama.

Celemin, J., Diana Martínez, Carlos Vargas, Margarita Bedoya y Clemencia Ángel (2016), Toma de conciencia. Sentir, pensar y actuar, Bogotá, Publicaciones Fundación Saldarriaga Concha.

Clara, Miguel y César Vega (2020), "La noción de educación de calidad a nivel superior: una reflexión desde el discurso del desarrollo", Interconectando Saberes, vol. 5, núm. 10, pp. 67-82.

Contreras, José (2006), "La autonomía docente: implicaciones para la formación del profesorado", en La formación del profesorado y la mejora de la educación. Políticas y prácticas, Madrid, Octaedro, pp. 241-264.

Dabezies, Lucia (2013), “Aportes para pensar lo comunitario en el programa maestros comunitarios (CEIP, Mides)", Ponencia presentada en las V Jornadas de investigación, IV Jornadas de extensión y III Encuentro de egresados y maestrandos, Montevideo, Universidad de la República de Uruguay.

De Sousa Santos, Boaventura (2011), "Introducción: las 
epistemologías del sur", en Formas-Otras: Saber, nombrar, narrar, hacer, Barcelona, CIBOD, pp. 9-22.

Díaz, Rafael (2018), Las políticas educativas en Colombia en la era neoliberal, Madrid, Editorial Primera.

Estivalis, María, Joan Traver y Auxiliadora Sales (2016), "La escuela en el barrio. Cartografiando las necesidades de cambio socioeducativo", Aularia. Revista digital de comunicación, vol. 5, núm. 2, pp. 13-20.

Fandiño, Yamith (2017), "Formación y desarrollo docente en lenguas extranjeras: Revisión documental de modelos, perspectivas y políticas", Revista Iberoamericana de Educación Superior, vol. 8, núm. 22, pp. 122-143.

Fandiño, Yamith, Marisol Carreño y Óscar Porras (2019), "Disoñar la formación política del profesor colombiano", en La educación y el sujeto político. Aporte crítico, Bogotá, Ediciones Unisalle, pp. 95-121.

Farías, Miguel y Leonardo Véliz (2019), "Multimodal texts in Chilean english teaching education: experiences from educators and pre-service teachers", Profile: Issues in Teachers' Professional Development, vol. 21, núm. 2, pp. 13-27.

Flaborea, Roberta y Adry Manrique (2019), El maestro y su desarrollo profesional en Colombia. Abordajes desde la investigación, Bogotá, Universidad Externado de Colombia.

Foucault, Michel (2008), Las tecnologías del yo y otros textos afines, Argentina, Paidós.

Foucault, Michel (2005), La hermenéutica del sujeto, Madrid, Ediciones Akal.

Fraga, Eugenia (2015), "Walter Mignolo. La comunidad, entre el lenguaje y el territorio", Revista Colombiana de Sociología, vol. 38, núm. 2, pp. 167-182.

García, Dinorah (2015), "Actitud al cambio socioeducativo y práctica educativa. Un análisis multifactorial en población docente", Tesis doctoral, Valencia, Facultad de Psicología, Universidad de Valencia, España.

García López, José (2010), "El agente de cambio organizacional: su rol y propósitos", Contribuciones a la Economía, vol. 6, núm. 4, pp. 1-10, <https://www.eumed. net/ce/2010a/jmgl3.htm> [Consulta: enero de 2021].

García, Joaquín y Ángel García (2001), Teoría de la educación II. Procesos primarios de formación del pensamiento y la acción, Salamanca, Universidad de Salamanca.
García, María Inés (2009), "Poder”, en Mónica Szurmuk y Robert McKee (coords.), Diccionario de estudios culturales latinoamericanos, Buenos Aires, Siglo XXI Editores, pp. 211-214.

Gil, Rafael (2018), La formación docente: horizontes y rutas de innovación, Buenos Aires, CLACSO.

Giraldo, A. y C. Maya (2015), "Modelos de ecología de la comunicación: análisis del ecosistema comunicativo", Palabra Clave, vol. 19, núm. 3, pp. 746-768.

Giroux, H. (2017), "Los profesores como intelectuales públicos. Paulo Freire", Revista de Pedagogía Crítica, núm. 1, pp. 21-33.

Giroux, Henry (1997), Los profesores como intelectuales. Hacia una pedagogía crítica del aprendizaje, Madrid, Ediciones Paidós.

González, Libia y Herver Tibaduiza (2015), “El movimiento pedagógico en Colombia y la subjetividad del maestro a 20 años de la ley general de educación: grupo de historia de la práctica pedagógica”, Tesis de maestría, Bogotá, Pontificia Universidad Javeriana, <https://repository.javeriana.edu.co/bitstream/ handle/10554/18669/GonzalezAyalaLibiaIsabel2015. pdf? sequence $=3>$ [Consulta: junio de 2021].

González, Teresa (1993), "La figura del maestro en la historia del pensamiento pedagógico", Revista interuniversitaria de formación del profesorado, núm. 16, pp. 135-144.

González, Víctor (2019), "Ser maestro hoy", Cuadernos Pedagógicos, vol. 21, núm. 27, pp. 6-16, <https:// revistas.udea.edu.co/index.php/cp/article/ view/337199/20792506> [Consulta: junio de 2021].

Gutiérrez, Yolima (2012), "Ausencias de una enseñanza reflexiva y sistemática de la oralidad", Revista Iberoamericana de Educación, núm. 59, pp. 223-239.

Hernández, Blanca e Iván Toro (2017), "Foucault y el cuidado de sí mismo: una posibilidad para la gestión humana", Revista Espacios, vol. 38, núm. 53, pp. 3549, <https://www.revistaespacios.com/a17v38n53/ a17v38n53p35.pdf> [Consulta: junio de 2021].

Herrera, Lina (2014), "Reflexión sobre el sujeto que podría encarnar el maestro en una intención de formación y 
de narración estética de sí", Ciencias Sociales y Educación, vol. 3, núm. 5, pp. 59-78.

Honoré, Bernard (1980), Para una teoría de la formación, Madrid, Ediciones Narcea.

Lamus, Doris (2007), "Diálogos decoloniales con Ramón Grosfoguel: trasmodernizar los feminismos", Tabula Rasa, núm. 7, pp. 323-340.

Lenis, José (2008), "Procesos de construcción de autonomía en docentes: tensiones entre discursos y prácticas", Educación y Cultura, núm. 78, pp. 106-108.

León, Ana (2013), "El maestro como sujeto político: dilemas entre los imaginarios y su formación", Revista Infancias Imágenes, vol. 12, núm. 1, pp. 117-123.

Loaiza, Yasaldez (2018), "Los maestros y la pedagogía", Revista Latinoamericana de Estudios Educativos, vol. 14, núm. 1, pp. 7-13.

Londoño, David (2014), "De la lectura y la escritura a la literacidad: una revisión del estado del arte", Anagramas, vol. 13, núm. 26, pp.197-220.

Magnusson, Petra y Anna-Lena Godhe (2019), "Multimodality in language education -implications for teaching", Designs for Learning, vol. 11, núm. 1, pp. 127-137.

Martín-Barbero, Jesús (2000), "Retos culturales de la comunicación a la educación", Nueva sociedad, núm. 169, pp. 33-43.

Martínez Boom, Alberto (2008), "Rostros y rastros del maestro contemporáneo", Quaestio, vol. 10, núm. 1, pp. 41-70, <http://www.albertomartinezboom.com/ escritos/articulos/2008_Rostros_y_rastros_del_maestro_ contemporaneo.pdf> [Consulta: junio de 2021].

Martínez, Elkin (2011), Neoliberalismo y educación en Colombia. Tres décadas de desfinanciación de la educación pública, Madrid, Editorial académica española.

Martínez, María Cristina (2006), "La figura del maestro como sujeto político: el lugar de los colectivos y redes pedagógicos en su agenciamiento", EDUCERE, vol. 10, núm. 33, pp. 243-250.

Medina, Patricia (2018), "Movimientos sociales y educación. Resonancias desde México", Polifonías Revista de Educación, vol. 7, núm. 12, pp. 169-205, <http://www.polifoniasrevista.unlu.edu.ar/sites/
www.polifoniasrevista.unlu.edu.ar/files/site/Medina. pdf> [Consulta: junio de 2021].

Méndez, Pilar (2014), "El estatuto del maestro", Revista colombiana de educación, 67, pp. 67-88, <http://www. scielo.org.co/pdf/rcde/n67/n67a04.pdf> [Consulta: junio de 2021].

Mendoza, Javier (2018), "Políticas y reformas educativas en México, 1959-2016", en Patricia Ducoing (coord.), Política educativa y educación básica, México, UNAM-IISUE, pp. 51-76.

Mignolo, Walter (2010), Desobediencia epistémica: Retórica de la modernidad, lógica de la colonialidad y gramática de la descolonialidad, Buenos Aires, Ediciones del Signo.

Miguel-Revilla, D. y M. Sánchez-Agustí (2018), "Conciencia histórica y memoria colectiva: marcos de análisis para la educación histórica", Revista de Estudios Sociales, núm. 65, pp. 113-125.

Muñiz, Lucía (2018), "El lugar de enunciación: sobre la realidad de la interpretación histórica", Euphyía. Revista de filosofia, vol. 10, núm. 18, pp. 9-30.

New London Group (2000), "A pedagogy of multiliteracies: designing social futures", en Bill Cope y Mary Kalantzis (eds.), Multiliteracies: literacy learning and the design of social futures, New York, Routledge, pp. 9-37.

Nieva, Jose y Orietta Martínez (2016), "Una nueva mirada sobre la formación docente", Revista Universidad y Sociedad, vol. 8, núm. 4, pp. 14-21.

Ortiz, Blanca (2006), "La formación de educadores: un acercamiento a las reflexiones teóricas", Revista del Centro de Investigaciones y Desarrollo Científico, núm. 7, pp. 251-267.

Osses, Sonia (2016), "La investigación: hacia la autonomía profesional docente", Portal Magisterio, <https://www. magisterio.com.co/articulo/la-investigacion-hacia-laautonomia-profesional-docente $>$ [Consulta: enero de $2021]$.

Padilla, Euclides (2014), "Neoliberalismo y educación", Revista de lenguas modernas, núm. 20, pp. 337-370.

Panotto, Nicholas, E. Cecchetti y A. Tedesco (2020), "Decolonizar el saber en la investigación en educación: el pensamiento-otro como estrategia epistémica para 
la producción académica diversificada", Reflexão e Ação, vol. 28, núm. 2, pp. 209-223.

Pantoja, Paula, Yasaldez Loaiza y Rocío Posada (2013), "Ecos del ayer, el hoy y el mañana: la conciencia histórica como concepto y propuesta en la formación de licenciados en ciencias sociales", Revista Latinoamericana de Estudios Educativos, vol. 1, núm. 10, pp. 136-157.

Pascual, Javier (2019), "Innovación educativa: un proceso construido sobre relaciones de poder", Revista Educación, Política y Sociedad, vol. 4, núm. 2, pp. 9-30.

Plata, María Eugenia (2018), "Subjetividades docentes en tiempos de la excelencia educativa”, Colombian Applied Linguistics fournal, vol. 20, núm. 2, pp. 290-302.

Riquelme, Angélica y Josefina Quintero (2017), "La literacidad, conceptualizaciones y perspectivas: hacia un estado del arte", Revista Reflexiones, vol. 96, núm. 2, pp. 93-105.

Rodríguez, Rosa (1998), El maestro colombiano: abnegado apóstol, funcionario estatal o trabajador de la cultura, Bogotá, Instituto para la Investigación Educativa y el Desarrollo pedagógico (IDEP).

Rojas, Carlos y Charol Gualteros (2018), "Pedagogías críticas latinoamericanas: una aproximación teóricoconceptual", Tesis de pregrado, Bogotá, Facultad de Educación, Universidad Pedagógica Nacional.

Romeu, Vivian y Maybel Piñón (2014), "La ecología comunicativa como germen de la comunicación estratégica. Hacia un estado de la cuestión", Razón y Palabra, núm. 86, pp. 1-18.

Salcedo, Javier (2017), "Reformas educativas y modos de subjetivación de docentes universitarios. Caso universidad de La Salle de Bogotá", Tesis doctoral, Bogotá, Doctorado interinstitucional en educación, Universidad Pedagógica Nacional, Colombia.

Saldarriaga, Óscar y Claudia Vargas (2015), "La configuración histórica del maestro público en Colombia: entre opresión y subalternidad, 18702002", Historia y Memoria de la Educación, vol. 1, núm. 1, pp. 287-318.

Sánchez-Amaya, Tomás (2013), "La evaluación educativa como dispositivo de constitución de sujetos", Revista
Latinoamericana de Ciencias Sociales, Niñez y Juventud, vol. 11, núm. 2, pp. 755-767.

Sánchez, Natalia, Erika Sandoval, Ruth Goyeneche, Danny Gallego y Leidy Aristizábal (2017), "La pedagogía crítica desde la perspectiva de Freire, Giroux, y Mclaren: su pertinencia en el contexto de Colombia y América Latina”, Revista Espacios, vol. 39, núm. 10, pp. 41-48.

Sharkey, Judy (2009), "Can we praxize second language teacher education? An invitation to join a collective, collaborative challenge", Íkala, Revista de Lenguaje y Cultura, vol. 14, núm. 22, pp. 125-150.

Suasnábar, Claudio (2017), "Los ciclos de reforma educativa en América Latina: 1960, 1990 y 2000”, en Claudio Suasnábar, Laura Rovelli y Emilia Di Pierro (coords.), Análisis de política educativa teorias, enfoques y tendencias recientes en la Argentina, Argentina, Editorial de la Universidad de La Plata, pp. 8-36.

Taylor, Bruce (2012), "Multiliteracies: moving from theory to practice in teacher education course", en Developing technology-rich teacher education programs: key issues, Nueva York, Information Science Reference, pp. 266-287.

Vallejo, Sofía (2020), "Movimientos sociales: conciencia social y acción colectiva", Revista El outsider, vol. 5, pp. 59-70, <https://revistas.usfq.edu.ec/index.php/ eloutsider/article/view/1577/1862> [Consulta: junio de 2021].

Velásquez, Zugey (2009), "Nuevos giros epistémicos para superar el modelo positivista de la disciplinariedad en las ciencias sociales", Utopia y Praxis Latinoamericana, vol. 14, núm. 46, pp. 143-157.

Vieira, Flavia y María Moreira (2008), "Reflective teacher education towards learner autonomy: building a culture of possibility", en Manuel Jiménez y Terry Lamb (eds.), Pedagogy for autonomy in language education: theory, practice, and teacher education, Dublín, Authentik, pp. 266-282.

Villegas, Luz (2008), "Formación: apuntes para su comprensión en la docencia universitaria”, Profesorado, Revista de currículum y formación del profesorado, vol. 12, núm. 3, pp. 1-14. 
Villegas, María Margarita (2014), "La perspectiva histórico-cultural y su impacto sobre la investigación de la docencia", Revista Actualidades Investigativas en Educación, vol. 14, núm. 1, pp. 1-17.

Zabalza, Miguel (1990), "Fundamentación de la Didáctica y del conocimiento", en Antonio Medina y María Luisa Sevillano (coords.), Didáctica- adaptación: el currículum.
Fundamentación, diseño, desarrollo y evaluación, Madrid, UNED, pp. 85-220.

Zemelman, Hugo (1998), Sujeto: existencia y potencia, México, Anthropos/CRIM-UNAM.

Zemelman, Hugo y Emma León (1997), Subjetividad: umbrales del pensamiento social, México, Anthropos/ CRIM-UNAM.

\section{Cómo citar este artículo:}

Fandiño-Parra, Yamith-José (2022), "De formación docente hacia subjetivación del maestro. Un giro epistémico necesario en el siglo XXI", Revista Iberoamericana de Educación Superior (RIES), vol. XIII, núm. 36, pp. 138-159, DOI: https://doi.org/10.22201/ iisue.20072872e.2022.36.1188 [Consulta: fecha de última consulta]. 